\title{
Afeto na educação: transgredindo o lugar de professor/a
}

\author{
Affect in education: transgressing teacher's place
}

\section{Afecto en la educación: transgredir el lugar de/de la professor/a}

Anna Carolina loras

https://orcid.org/0000-000I-957I-5479

Thiago Colmenero Cunha ${ }^{2}$

https://orcid.org/0000-000 I-8202-3377

\begin{abstract}
Resumo: $O$ presente trabalho faz uma reflexão sobre a relação educador/a-estudante e os afetos que a circundam, bem como olhar para o quão potente este encontro pode ser. Investiga-se aqui uma proposta de cuidado, que integra a/o estudante, de forma a agregar ao processo educacional as intercorrências da vida, os múltiplos processos de produção de subjetividade. Alinhado às discussões baseadas na psicologia educacional crítica, na educação popular e na educação antirracista, aposta-se nesse manuscrito em uma educação que potencialize trocas contínuas de saberes afetivos e pedagógicos, um modelo de educação que integra corpo e mente, que não visa somente racionalizar o desenvolvimento humano. Através de um relato de experiência localizado e embasado na literatura científica, o texto apresenta compilados relacionais entre vivências escolares dos pesquisadores. Entendendo as práticas educativas a partir das relações e com base nos inúmeros afetos que circulam esses encontros, defende-se aqui uma educação com respeito ao que nos atravessa, uma educação vivencial, relacional e por consequência horizontal.
\end{abstract}

Palavras-chave: Afeto. Educação libertária. Cuidado.

\begin{abstract}
This paper reflects on the relationship between educator and student and the affections that surround it, as well as looking at how powerful this encounter can be. We investigate here a care proposal, which integrates the student, in order to add to the educational process the complications of life, the multiple processes of production of subjectivity. Aligned with discussions based on critical educational psychology, popular education and anti-racist education, this manuscript is betting on an education that enhances continuous exchanges of affective and pedagogical knowledge, a model of education that integrates body and mind, which is not only aimed at rationalizing human development. The text presents relational compilations between school experiences of the researchers. Understanding educational practices based on relationships and based on the countless affections
\end{abstract}

\footnotetext{
I Psicóloga. Educadora em Educação Infantil. E-mail: anna.ioras@gmail.com.

2 Doutor em Psicologia (UFRJ). Professor dos cursos de graduação em Psicologia, em Pedagogia e em Direito da Universidade Santa Ursula (USU). E-mail: colmenerocunha@gmail.com.
} 
that circulate in these encounters, we defend here an education with respect to what goes through us, an experiential, relational and, consequently, horizontal education.

Keywords: Affection. Libertarian education. Care.

Resumen: Este trabajo reflexiona sobre la relación entre educador y alumno y los afectos que la rodean, además de ver lo poderoso que puede ser este encuentro. Investigamos aquí una propuesta de cuidado, que integra al alumno, con el fin de sumar al proceso educativo las complicaciones de la vida, los múltiples procesos de producción de subjetividad. Alineado con discusiones basadas en la psicología educativa crítica, la educación popular y la educación antirracista, este manuscrito apuesta por una educación que potencie los intercambios continuos de saberes afectivos y pedagógicos, un modelo de educación que integra cuerpo y mente, que no solo tiene como objetivo racionalizar desarrollo humano. El texto presenta recopilaciones relacionales entre experiencias escolares de los investigadores. Entendiendo las prácticas educativas basadas en las relaciones y en base a los innumerables afectos que circulan en estos encuentros, defendemos aquí una educación con respecto a lo que pasa por nosotros, una educación vivencial, relacional y, en consecuencia, horizontal.

Palabras claves: Afecto. Educación libertaria. Cuidado.

\section{Experienciando os afetos visceralmente: uma introdução}

Este artigo propõe-se a contar outras histórias sobre modos de educar, partindo principalmente de nossas implicações. Meus questionamentos sobre o modelo educacional em que me inseria começaram no ensino fundamental, por volta dos 13 anos de idade. Estudava em uma escola pública da Zona Sul do município do Rio de Janeiro. Ao lado havia uma outra escola: privada, bilíngue, de classe média alta, onde os/as estudantes não tinham contato conosco, já que os horários de entrada e saída eram diferenciados e só podiam sair de seus veículos exatamente na porta da escola. Essa delimitação de espaços, a segregação por classes - mesmo sem saber teorizar isto - já me atravessava de alguma forma. Então meus olhares voltaram-se para o que acontecia dentro do ambiente em que frequentava. Para o que se estabelecia entre as relações na minha escola. A cobrança da instituição para com os/as estudantes, quanto a disciplina e interesse pelos conteúdos oferecidos; bem como a cobrança dos/das estudantes para com os/as professores/as, em prol de mais dedicação e busca de alternativas para sair do padrão de aula expositiva.

Minha escola localizava-se em uma casa antiga e pequena, com pouca infraestrutura escolar, principalmente para receber os/as estudantes grandes, adolescentes. A parte externa, isto é, o pátio, era bem limitada, de forma que não suportava atividades físicas coletivas, sem que fosse cerceado o espaço dos/das outros/outras estudantes, em horário de intervalo.

As aulas de educação física também eram impedidas por não comportar as propostas dos/das professores/as e também limitar o alcance de capacidade dos/das estudantes, vide o tamanho dos/das mesmos/as e o espaço disposto. Era praxe os/as professores/as dessa disciplina recorrerem aos exercícios teóricos, tendo em vista os obstáculos estruturais e/ou nos liberar de tarefas naquele tempo de aula e assim ficarmos livres pela a escola. Mesmo sendo esse momento, o único que desfrutaríamos de outra atividade que não intelectual. 
Por conta da atitude da administração da escola para esta situação, por vezes reivindiquei por essas aulas, assim como buscava justificativas e ocupações para a turma, nesse período. Também o fazia no caso de ausência de alguma outra aula/educador/a - então, se construía o estigma de "chata" e/ou “do contra". De fato, não sabia até então, as reais questões da instituição para agir dessa maneira frente aos imprevistos. Mas o que transparecia na época, era um descaso com nosso tempo e dispêndio de energia para um cronograma de aulas diárias, estabelecido pela escola e repassado aos/às estudantes desde o início do ano.

Desde de então, já acreditava que a escola era mais que um lugar comum, que todes ${ }^{3}$ precisam frequentar durante parte de sua vida para aprender teorias que podem ou não ser base de um futuro acadêmico e profissional. Segundo Dayrell (2003), é preciso entender o ambiente escolar como um todo, tendo em vista todas as pessoas que o compõe, bem como os espaços físicos e principalmente a relação entre todes esses atores, como um espaço sociocultural de convivência e de partilha. Um lugar de formação de valores, de conhecer diferentes histórias, vivências, realidades; principalmente em uma escola pública como era a minha, mesmo está sendo um tanto elitizada, já que se localizada em área nobre da cidade.

A frequência dos/das estudantes era de filhos/as de militares, estrangeiros/as, gerações de famílias que há anos estudaram na mesma escola, além dos/das que moravam no entorno. Mas, justamente, pelo suposto estereótipo de que quem mora na zona sul é mais bem-educado, muitas famílias, mesmo residindo longe, insistiam em matricular seus filhos/as nesta escola, no intuito de terem supostas melhores influências. Eu residia na Zona Sul, com minha mãe e madrinha. Esta última era, ao mesmo tempo, prima e patroa da minha mãe, empregada doméstica da casa onde morávamos.

Ao chegar ao final do ensino fundamental me responsabilizei por meu caminho acadêmico e fui em busca de oportunidades que visavam a educação em sua completude, aprendizagem de conteúdos em conjunto com rede de relações. Passei por curso preparatório ${ }^{4}$ para escolas de ensino médio/técnico, com ênfase em competição por melhores resultados, não obtive sucesso. No entanto as vivências relacionais que tive nesse período marcaram minha trajetória.

Experimentei de forma mais vívida a corrida para "ser alguém na vida". Ainda não havia ressignificado essa frase quando não obtive resultados satisfatórios nos concursos para as "melhores" escolas e me frustrei. Por sorte (ou não), como estudava numa escola bem-conceituada do munícipio,

\footnotetext{
3 Todes: Política de escrita sem direcionamento a um gênero específico.

${ }^{4}$ Curso extracurricular a fim de preparar os/as estudantes para provas de concursos de instituições de ensino médio, bem pontuadas na classificação geral da educação. Regionalmente no Rio de Janeiro, como por exemplo: Colégio Pedro II, Instituto Federal do Rio de Janeiro (IFRJ) e Centro Federal de Educação Tecnológica Celso Suckow da Fonseca (Cefet-RJ).
} 
era uma das poucas que tinha convênio com uma escola particular, francesa, tradicional, também na Zona Sul e considerada muito boa segundo as classificações das escolas públicas e privadas, estaduais 5 . Muitos/as de meus/minhas colegas de classe foram para a mesma escola, mas eu ainda tinha o estigma de "chata", por não me adequar ao padrão ou me conformar com regras que não me representavam. Apesar de estar no padrão estético e normativo (magra, loira, hétero e cisgênero), minha realidade era muito diferente de grande parte dos/das estudantes da escola. Era como se eu estivesse do outro lado do muro da minha escola anterior. Agora, sendo também uma integrante de uma escola privada, com núcleo de pessoas que segregam por níveis sociais, cargos de trabalho e/ou nível de escolaridade. Apesar de não ser a intenção generalizar as histórias que se encontravam naquele ambiente, o que relato era $o$ afeto que me atravessava naquele momento.

Em paralelo à minha experiência, vi muitos/as dos/das colegas que vieram de escolas públicas como eu, viverem uma mistura de afetos com os obstáculos relacionais e avaliativos. As provas eram niveladas pelo ensino da escola em geral. No entanto, nossa base de escola pública estava muito aquém para nos dar suporte nessas avaliações. Ao nos depararmos com as notas de provas, trabalhos, boletins, chorávamos pela escola e/ou em casa. Como talvez, não fizéssemos tanto no dia a dia, nesses momentos, uníamos nossas histórias e fortalecíamos uns/umas as/aos outros/as. Com a esperança de que ainda havia outra oportunidade de recuperarmos as notas.

Essa harmonia entre os/as bolsistas e a junção de nossas realidades durava pouco. Os deslumbres com um padrão de vida tão acima do nosso e tão próximo de nós diariamente, fazia esquecer a possibilidade de tudo acabar. Já que a escola desqualificava a/o estudante bolsista, do direito adquirido de bolsa integral, caso reprovasse nas disciplinas exigidas.

Segundo, Flávia Timm e Ondina Pereira (2016), trazendo a filosofia da imanência do holandês Baruch Spinoza, os afetos nos equilibram ou desequilibram, em resposta aos estímulos do mundo. $E$, era assim, que respondíamos aos obstáculos e novidades de um ambiente hostil e ao mesmo tempo encantador - enquanto bolsistas de escola particular.

$\mathrm{Na}$ verdade, era invadida todos os dias por diversos questionamentos relacionais, tanto entre os/as estudantes, quanto a escola; além dos meios em que fazia parte, na época. Como, qual lugar eu ocupava naquela escola de pessoas com nível social tão acima do meu; com colega de classe que ao chorar por não alcançar a nota máxima - mesmo já estando bem acima da média - a família diz para ir ao cinema espairecer, por exemplo; uma escola, a qual obrigava os/as estudantes a levantar quando o coordenador entrava em sala de aula, para o cortejar dizendo "Bom dia, coordenador (o nome do

\footnotetext{
${ }^{5}$ No Brasil, os municípios são responsáveis pelo ensino infantil e fundamental e o Estado pelo ensino médio (LDB 9394/1996).
} 
mesmo)!"; ou quando se chegava atrasado mais de 15 minutos do horário de entrada, não permitiam assistir mais nenhuma aula do dia e caso o ocorrido se repetisse por três vezes, só voltaria a frequentar as aulas quando um responsável comparecesse à escola. Por fim, fui reprovada em quatro matérias e perdi o direito de bolsa integral. Logo, saí da escola, por não ter nenhuma possibilidade de pagar qualquer valor. Vi muitos colegas tendo o mesmo desfecho. E, ao contrário da união de outrora, por conta das notas baixas e do medo de perder o direito a bolsa de estudos, tomaram suas frustrações e conformidades para si e seguiram seus percursos individualmente.

Os encontros promovidos pelo ambiente escolar, principalmente quando há identificação por semelhança de histórias, são extremamente enriquecedoras. Envoltas por muito afeto, simbolizam significativamente nossas trajetórias.

Terminei o ensino médio pelo EJA (Educação de Jovens e Adultos) numa instituição privada, com bolsa integral. Apesar de privada, a instituição apresentava um perfil específico como público. Grande parte dos/das estudantes eram adultos, trabalhadores e que tinham a necessidade do diploma do ensino médio para algum fim profissional. No entanto, muitos já tinham saído da escola há anos e tinham dificuldades básicas, ou por cansaço do trabalho não conseguiam se dedicar como gostariam à escola. Neste cenário, me percebia muito à frente dos/das outros(as) estudantes. Tinha acabado de sair de uma escola, com foco no vestibular. Logo, a demanda de resultados era rigorosa, com média de avaliação alta. Então meu despontar frente ao conteúdo do EJA foi rapidamente notado pelos(as) professores(as).

Envolta pelo afeto de fracasso escolar íntimo e desapontamento com as escolas pelas quais passei, além de questões financeiras e emocionais, não tinha ânimo para ingressar no ensino superior, mesmo sonhando com este título. Então, após cinco anos, mais madura enquanto mulher, consegui iniciar um curso universitário. Com receio de perder mais tempo, não me identificando com o curso escolhido, fiz uma orientação vocacional, a qual resultou o curso de Psicologia.

A faculdade me proporcionou encontros com pessoas, ambientes, áreas de conhecimento nunca antes pensada por mim. Um processo de imersão às inúmeras possibilidades pessoais e profissionais. Me permiti conhecer caminhos distintos, como Saúde Mental e Recursos Humanos. Mas sempre atravessada pela educação na prática de ambos. Até que então decidi deixar transbordar os muitos afetos que nutria pela área educacional e fui atuar como educadora da primeira infância, com a faixa etária de I a 3 anos de idade.

Discorrer sobre as intercorrências do meu caminho escolar, me faz repensar e me conectar com minha prática educacional. E, tomar consciência do impacto que posso causar, no desenvolvimento de cada criança, quando me disponibilizo a ser ponte entre as mais diversas possibilidades de ser. No lugar de educadora posso ser estímulo e reação, a própria potência do afeto. 


\section{Aprender-fazendo, fazer-aprendendo: uma metodologia}

O presente trabalho parte dos relatos da minha vivência escolar, diários de campo da minha vivência como educadora hoje e os encontros que tive por conta da imersão na área. Fatores que me levaram a ressignificar o papel de professor(a), educador(a) e o que entendia por educação. Além de uma revisão bibliográfica de autores e trabalhos que me inspiraram a ser integrante de experiências e futuras memórias, dos/das "meus"/"minhas" estudantes/crianças.

Baseada em uma imersão ("O ser singular na educação", ministrada por Ivana Jauregui e Ana Thomaz), tive um encontro com a metodologia de Educação Viva e Consciente. Nesta acredito ter transmutado a carência de afetividade na educação - partindo de minha vivência - pelo atravessamento do afeto de completude, em virtude do lugar que ocupo hoje enquanto educadora. Assim, vendo a possibilidade de ser facilitadora de espaços e diálogos em prol da educação livre. A cooperar com a parte teórica-vivencial da imersão, a mesma aconteceu em uma casa antiga, em meio a natureza, com cheiro de madeira e floresta, café e sons de passarinhos, na Zona Sul do Rio de Janeiro, onde é locada uma escola. Tudo se tornava vetor do início de uma narrativa particular se despontando ali. Um espaço convidativo à observação e ao deixar-se envolver pelos afetos que reverberam intimamente.

Como exemplo deste modelo temos a Escola Inkiri, localizada na comunidade Inkiri Piracanga, em Maraú, Bahia. Esta que acompanho via redes sociais e contato com pessoas que fizeram parte dessa construção, com a Ivana Jauregui. Inkiri, significa "o amor em mim saúda o amor em você" e faz menção de uma tribo indígena que viveu à beira do Rio Piracanga há cerca de 700 anos.

A comunidade Inkiri Piracanga, tem como proposta honrar a forma simples de viver, como esta tribo pregou a tantos anos. De forma que a consciência de si no aqui e no agora prevaleça. Um lugar disposto a oferecer às crianças liberdade de se expressar e vivenciar suas experiências de acordo com seu fluxo de interesse (PIRACANGA, s/a).

Como é relatado no livro "Educação Consciente - Escola Viva Inkiri” (INKIRI, 20I4) inicialmente o projeto se inspirou na Escola da Ponte, em Portugal e na Fundação Pestalozzi, no Equador. Com o desenvolver das atividades a escola foi se tornando um organismo vivo e ganhando autonomia em sua pedagogia. Transcendendo as inspirações primeiras, emergiu a Pedagogia Inkiri, um conceito de escola livre e libertária. Um modelo de educação que respeita a singularidade e o desenvolvimento de cada um. Uma junção de ambiente e educadores/as, a qual possibilita que cada indivíduo seja o que é, nas dimensões que entendem constituir um sujeito: "ser (eu comigo), social (eu com o outro), planetária (eu no mundo)" (Piracanga, s/a).

Segundo o livro "Educação Consciente - Escola Viva Inkiri” (INKIRI, 20I4), os/as adultos/as, sejam eles/elas educadores/as ou não, são responsáveis por dar suporte emocional às crianças. 
Estarmos presentes por inteiro, em prol do cuidado afetuoso. Sermos generosos em sensibilidade, para uma escuta atenta, um olhar minucioso e aberto ao atravessamento dos afetos que percorrem o dia a dia. Enxergar além do que se expressa, as linhas de forças dessas subjetividades. Para ser sustento do outro, é necessário o autocuidado. Ser tão gentil conosco, quanto com nossas crianças. Logo, o processo de autonomia é construído em cima de vínculos sinceros e confiança mútua.

Embasada no conhecimento psicológico - científico e clínico -, o modelo de educação livre e a crença de que a existência humana depende do ato relacional, como diz a educadora bell hooks (2007), começo a observar minha prática escolar. Atenção aos discursos, às trocas de afetos, o acolhimento às demandas, frente às crianças e também aos/às adultos/as que compõem a instituição que trabalho. Percebo a reprodução das minhas falas/jargões, como por exemplo, quando eles/elas conseguem pôr os sapatos e eu digo "- Arrasou! Bate aqui!" (batemos as mãos); ou o quanto são sensíveis aos afetos que me atravessam, acessando pelo tom da minha voz.

A partir da disciplina de "Psicologia educacional e problemas de aprendizagem" da faculdade, fui impactada em reconhecer em mim o preconceito que tinha, e por consequência a negação, de que enquanto psicóloga não poderia ocupar o lugar de educadora. $O$ encontro com a educadora que ministrava a aula, Debora Lomba, psicóloga e pesquisadora da área educacional, bem como as implicações que a mesma fomentava na turma, me fez repensar este posicionamento. Então é dado início a um processo de ponderação entre os questionamentos da vivência escolar e as propostas teóricas que são dispostas a conhecer naquele momento, por intermédio da graduação de Psicologia e em conjunto com o que aqui trazemos como apostas em uma forma ética de educação. Com a proposta de debater sobre uma educação livre e humanizada, se faz o presente trabalho.

As irregularidades do dizer, as tensões, a entonação, os imprevistos, as variações de altura, os movimentos corporais, os silêncios, os cheiros do ambiente, a mímica, constroem os cenários de pesquisa aqui relatados ganhando cores e tons mais vivos. Expressões e falas contagiadas de surpresa, desconcerto ou espanto dão pistas de momentos em que a experiência se apresenta mais intensamente. Ética de fazer e estar junto. Identidade a partir da linha de construção do pertencimento, não da exclusão do supostamente diferente, nem também da construção de uma reunião dos idênticos a si mesmo. Uma constante composição no campo altera a produção de saberes de pesquisa que atravessam os pesquisadores e o texto, como nos afirma Vilene Moehlecke (2012). Através do método cartográfico de pesquisa (MORAES, 20I0; PASSOS, KASTRUP, ESCÓSSIA, 20I5) aposta-se aqui no envolvimento como caminho, no enredar-se, sem distinção entre o dentro e o fora, há apenas participação e estar junto. Um acompanhar das singularidades que constroem e inventam novas realidades, aqui relatadas nesses múltiplos processos de fazer-se educador/a. Para isso aqui, são trazidos relatos de experiência localizados, aliados à literatura cientifica contextual e aplicada à área. 


\section{Pensando a educação como um ato relacional}

Lembro como se fosse hoje de quando criticava os/as educadores/as por não serem sensíveis aos/às estudantes e seus reais interesses. As aulas em sua maioria expositivas, em que o educador/a se posiciona em frente à turma, com carteiras enfileiradas, para explicar a matéria posta no quadro; enquanto os/as estudantes aceleram a cópia dos escritos no caderno, antes que acabe a aula. Falta de ferramentas atuais e criativas para passar o conhecimento? Cansaço. Estresse. Falta de recursos básicos. Tudo isso bem claro para os/às estudantes. Às vezes verbalizado, como a comparação de nível de interesse e disciplina, feita por um/a professor/a, em relação a minha turma, de escola pública e os/as estudantes da escola ao lado, privada, bilíngue e composta por crianças de famílias com alto poder aquisitivo. Em contrapartida, já justificava o posicionamento dos/das professores/as afirmando a suposta falta de prazer dos/das mesmos/as, pelo ofício escolhido, como se tudo aquilo fosse culpa deles/delas.

Hoje, analisando minha opinião da época, me chama atenção os termos "sensível", "reais interesses" e "prazer". Aqui temos características geradoras de um movimento cíclico. A sensibilidade de um indivíduo frente a alguém ou algo, demanda implicação pelo menos de uma das partes sobre a outra. Implicação aqui é utilizada a partir dos estudos da Análise Institucional Francesa, onde se critica uma posição distanciada, neutra, desencarnada, não contextualizada, sem análise, não localizada do/da pesquisador/a, do/da profissional, do indivíduo. Mais do que pensar razões, quantidades, justificativas e explicativas, isto é, os 'porquês' das ações e dos fatos. René Lourau (1993) traz a importância de colocar em análise e mapear as intensidades, as relações de poder, as qualidades, os afetos, os 'comos' das nossas presenças e intervenções. Implicar é dobrar-se, articular-se a algo novo que produz mudanças e alterações; é operar uma transformação. Para que isto aconteça tende haver interesse dos indivíduos desta relação. Logo, o prazer se torna indispensável para que o movimento se dê.

Tendo em vista a implicação necessária de ambas as partes, para que se estabeleça o cuidado mútuo, é sensível reconhecer que o/a estudante é parte desse processo de aprendizagem. Dar ouvidos, corpo e espaço para que os/as mesmos/as se sintam à vontade de cuidar uns/umas dos/das outros/outras, inclusive do/da educador/a. E, então, se torne rotina, o respeito mútuo.

A escola moderna conteudista e bancária ainda se baseia como provedora da educação e de desenvolvimento humano. Quando muita das vezes, na prática, a ênfase recai sobre o desenvolvimento intelectual. No entanto, as relações diárias dentro e fora do ambiente escolar constroem vínculos emocionais que fortalecem, tornam-se mais ou tão relevantes quanto o aprendizado teórico. Se partirmos da posição de que a escola é uma rede ou teia social, deixamos de colocar o/a educador/a como único/a detentor/a de autoridade e sabedoria. E, então, o lugar de educador/a se horizontaliza por todes os/as que se responsabilizam pelo cuidado na escola (SANTOS, 2015). 
Tive muita dificuldade de me relacionar na escola até meados do ensino fundamental. Até então, residia em uma cidade serrana no Rio de Janeiro, Petrópolis. Pelas escolas onde passei, quando havia amizade, geralmente era com adultos/as. Como na última instituição que estudei antes de me fixar na cidade do Rio de Janeiro, em que o único momento prazeroso do dia era o intervalo. Não porque me divertia com as outras crianças, mas sim porque conversava com meu amigo, inspetor da escola. Enquanto fazia seu trabalho, fiscalizando as crianças pelo pátio, eu andava atrás dele para conversarmos.

Lanchava e esperava o único horário de liberdade e euforia entre os/as estudantes passar, para assim poder voltar para sala de aula. Ao retomar esta memória, sou atravessada por afetos tristes em não ter pessoas próximas, enquanto estudantes também. No entanto, também me atravessa o afeto alegre de ternura desse inspetor. Um encontro de cuidado, talvez não percebido por ambas as partes, na época, e com alguém não diretamente ligado ao núcleo pedagógico. Mas que disponibilizou tempo, em seu horário de trabalho de maior demanda, em prol de escutar e acolher minha solitude.

As relações começaram a se estabelecer quando ingressei em uma escola no Rio de Janeiro e lá permaneci até findar o ensino fundamental. Inicialmente não conseguia conversar com os/as colegas de turma, sempre muito calada, era extremamente tímida, tinha medo de como reagiriam com uma pessoa vinda de outra cidade com modos diferentes de falar, por exemplo. Além da lida com os colegas de classe, também não tinha diálogo com os/as educadores/as e/ou adultos/as da escola. Era tudo muito novo e ingressei nesta instituição no meio do ano letivo. Logo, os vínculos já estavam firmados e o caminhar das atividades curriculares estabelecidos.

Com o passar do semestre, vieram as primeiras provas. A timidez me assolava, por isso não conseguia tirar dúvidas, ou se quer prestar atenção nas aulas. A atenção e tensão estavam voltadas para as relações e as supostas chances de ser posta em exposição por algo ou alguém. Na primeira avaliação, de matemática, não sabia absolutamente nada. Era como se até os números fossem uma novidade. Passei todo o tempo olhando para minha prova e para os/as outros/as estudantes, que escreviam, apagavam, escreviam novamente e terminavam suas avaliações. Ao perceber que ficava entre os últimos da turma, meu coração palpitava, suava e por fim, quando só restava a mim na sala, chorei com a professora. Entreguei a prova em branco, saí da sala para me juntar a turma com o rosto marcado pelo choro. Então os/as estudantes da turma me acolheram, me acalmaram e se propuseram a me ajudar para a próxima prova. A partir desse momento de vulnerabilidade o campo se abriu para as conversas e trocas. A confiança no espaço como um todo, me deu segurança de expor minha opinião ou de tirar dúvidas, por exemplo. Os vínculos de amizade se iniciaram.

Uma forma de educação que aposte na compressão entre a relação educador/a-estudante e restrita entre quatro paredes, limita possibilidades de existência, limita formas de respirar, limita formas 
de criar e ver o mundo. Uma sociedade determinada a seguir normas padronizadas que simbolizam a normalidade, em prol de conservar um ambiente hierárquico, com relação de poder entre detentores de mais e de menos conhecimento, a fim de engessar o modelo professor/a-tablado-quadro e carteirasestudantes. É uma transgressão epistemológica reconhecer que todes somos responsáveis pela educação, já que em qualquer relação estamos aprendendo e ensinando algo. Significa dar completude a este movimento. Apostar-fazendo e fazer-apostando que a sala de aula é o mundo, como diz Muniz Sodré, no documentário "Quando sinto que já sei" (20l4). Sendo assim, a escola não se fecha em seus muros e a educação frente a isso se torna partícula indivisível. Ou infinita, que provém do vazio das relações mais primitivas.

Um vazio como espaço de criação em sua infinita possibilidade. $O$ mesmo vazio que gera diferença, pois a criação se dá em relação, e a cada relação uma criação singular em sua multiplicidade. A criação se dá no vazio da relação, nesse "entre". Se a relação, no campo imaginário, já está pronta, determinada, previsível, preenchida, fica impossível criar (THOMAZ, 2019, p. I).

A educação pautada no ato relacional necessita de um espaço aberto e sensível para acolher e facilitar a descoberta das próprias potências. Mesmo com avanço tecnológico, o ser humano ainda depende do outro para as relações primeiras, de troca de afeto e suprimentos em prol da sobrevivência. Somos um conjunto de momentos de transferência mútua de conhecimento e emoção. É nessa disponibilização genuína para as relações, que emergem afetos, como empatia; e se iniciam processos, como de autoconhecimento. Para Mattos, Pérez, Almada e Castro (2013), entregar-se a este vínculo significa se afetar pela necessidade do outro e ser capaz de se movimentar em prol disso. Como educador/a preciso ter um corpo em contato com inúmeras e variadas possibilidades para/com os/as estudantes. Estar neste lugar é compilar uma gama de teorias, com o atravessamento dos afetos. Ao passo que se atende a necessidade de um, têm também um grupo que depende do meu dispêndio de energia e cuidado. Uma demanda delicada e dependente da troca de afetos das partes, sempre em conexão com tudo que está à volta.

Divisão de grupos para melhor aproveitamento das atividades. No corredor da escola, a metade da turma e eu. Nos organizamos para subir as escadas, eu na frente. Grupo agitado, voltando para sala depois de um período grande correndo pelo pátio. Uma das crianças começa a chorar descompassadamente, sem que eu veja o motivo. Um instante de desestabilização, crianças sensivelmente percebem, se dispersam e retornam ao pátio. Por hora, a dor, precisa ser acolhida. Vou amparar a criança que chora.

Os afetos que circundam esses momentos de disfunção energética entre o grupo, também gera movimento, ação. Agenciar este fluxo e acionar o senso de urgência, reverbera como exemplo 
de acolhimento a crise do outro. É externar para todes que ali se encontra apoio e aconchego quando necessário. Somos agentes de autonomia e também fonte segurança.

Se entregar ao ato de afetar é despir-se do saber; estar vulnerável a qualquer acontecer, como dizem Gislei Lazzaroto e Júlia Carvalho (20I2). Quando esses encontros acontecem nenhum dos/das envolvidos/as são mais os/as mesmos/as, pois naquele instante ambos/as se disponibilizaram a viver apenas aquele ato relacional. Possibilitar a emergência das histórias submersas de estudantes, de educadoras/es, da nossa população, de nós. Praticar uma percepção e uma audibilidade das diferenças de cultura, gênero, cor, etnia, orientação sexual, potências, habilidades, visibilidades. Ter como bússola ética essa perspectiva, descreve singularização, mas também, como nos diz a educadora Azoilda Trindade, coordenadora pedagógica do projeto “A Cor da cultura” (1999, 2006, 2010), de insurreição, inventividade, lutas, busca constante e incessante de alternativas: a potencialização de práticas profissionais e de pesquisa não alienadas do nosso contexto sócio histórico.

Segundo Luciana Soares (2015), o currículo de Psicologia quanto ao desenvolvimento humano, tem produzido expectativas em cima dos indivíduos, como base em conhecimento científico distantes das nossas realidades, majoritariamente brancos, europeus, normativos. Com a disseminação dessas verdades únicas, fomos inseridos/as em uma sociedade que naturaliza e reproduz tipos de normalidade. $E$ as escolas, no lugar de extensão da primeira instituição de uma criança, sua casa/família, muita das vezes alinha e amplifica este modo de pensar e viver, o que influencia diretamente nas relações intra e extraescolares.

\section{O adulto e o cuidar em sua totalidade}

Para além das necessidades básicas, fisiológicas e emocionais, é importante uma presença de qualidade. Isto, em prol de melhor alinhamento de seus desejos e dos limites, em sua formação. Estar presente completamente em cada momento, por mais difícil que seja uma situação, como por exemplo uma pirraça da criança, em espaço público. Faz parte do amor genuíno estar por completo em cada momento da criança (INKIRI, 20I4). É importante se manter disponível e firme em prol de passar segurança. E, também não se dispersar com opiniões alheias a qualquer situação direta entre adultos/as e criança. Esta presença é fundamental no cuidado inferido tanto para acolher as diversas demandas da criança, como a necessidade de dar limites; quanto para passar conteúdo pedagógico.

No âmbito escolar, comumente, há uma separação do adulto de referência para o cuidado e outro para a educação. Distanciando essas duas funções, como sendo distintas, negamos a coletividade de uma escola, o acolhimento e o afeto ao educar: "o cuidado envolve muitos atores, e não podemos dispensá-los ao analisarmos essa rede" (SANTOS, 20I5). 
Alinhar o cuidado à educação significa validar o saber intelectual e emocional da/do estudante; o processo real de desenvolvimento humano. Segundo Paulo Freire, patrono da educação brasileira (2005), muita das vezes os/as estudantes se tornam apenas depósitos de narrativas, que depois são reproduzidas por esses sujeitos, sem passar pelo movimento de pensar. Lisboa, Cunha e Bicalho (2018) discorrem sobre um processo de aprendizagem inventiva, o qual inclui, além do conteúdo cognitivo, as intercorrências naturais da vida. Quando o/a educador/a acolhe e torna fluido o conhecimento pessoal/vivencial do/da estudante, traduz em atos o respeito ao saber do outro.

Ao cuidado, atribui-se muitas qualidades e formas de ser promovido. Destacando a educação da primeira infância, é sim importante o cuidado primeiramente passar pelas necessidades fisiológicas e integridade física da criança. Mas além disso temos o respeito mútuo, a escuta e diálogo a fim de integrar esse cuidado. Marília Carvalho (1999) salienta que ao tirarmos o caráter conteudista da educação infantil abrimos espaço para observação das relações emocionais significativas, que se firmam entre adultos/as e a criança. Uma criança entregue às experiências propostas pelos adultos/as de seu convívio, ou segura de que é ouvida em suas demandas, é uma criança certa de que pode ser quem ela é e só.

Esse manuscrito e a autora, não tem a pretensão de romantizar o lugar de educador/a ou colocar aqui um ideal de profissional, justamente por ocupar este papel também. A rotina diária de uma escola demanda muitas tarefas burocráticas e atenção de forma generalizada com todo o grupo. E foi em um momento desses, que experimentei o cuidado mútuo. A devolutiva sensível de uma criança ao meu estado de preocupação.

Fui com minha turma, com a faixa etária de 3 anos, no Parque Lage, um parque público rodeado de florestas no bairro do Jardim Botânico, Zona Sul do Rio de Janeiro. Como educadora que baseia sua prática nas relações com as pessoas e com o ambiente, acredito que o conhecimento extramuros é uma das experiências mais deslumbrantes na vivência escolar e principalmente na educação infantil, bem como a potencialização do aprendizado mútuo de educador/a e estudante.

Somos pesquisadores/as, observadores/as, entregues ao nível de curiosidade do que nos chama atenção. Segundo Paulo Freire (20l6), a existência se dá, quando o corpo toma consciência da capacidade de transmutar, inventar, ver beleza e se preencher do que o instiga de fato e não só um ser vazio à espera de ser preenchido por conteúdo.

Estar fora do ambiente comum, bem como do lugar que fornece o mínimo de segurança por si só, como a escola, produz tensão e atenção redobrada. Contudo, após a intensa exploração dos/das pequenos/as pesquisadores/as, paramos para fazer nosso lanche coletivo. Auxiliamos as crianças a se organizarem com seus lanches e depois a guardarem seus recipientes para caminharmos ao fim da atividade. Foi quando uma delas entornou iogurte em sua lancheira. É uma criança que costuma estar 
agitada e dispersa. Então fui falar com ela com tom de desapontamento: "- Poxa, Felipe (nome fictício). O que aconteceu?" e, com toda calma e organização corporal, me respondeu: "- Caiu. Tudo bem, depois limpa", seguiu arrumando sua lancheira e depois retornou à atividade. Neste momento fui atravessada pelo afeto da criança ao me perceber tensa com a situação.

Então tomei consciência de tamanha experiência sensorial, que aquele dia estava sendo. Deixeime atravessar pelos afetos e assim, emergir o que meu corpo dizia. Me entreguei ao vento sobre a pele, o suor, o sol, a euforia, o cansaço, a compaixão, o amor, a alegria de estar ali e mais em lugar nenhum. Me fazer presente genuinamente para os muitos encontros que estavam acontecendo. Neste sentido, com um olhar sensível, conseguimos transgredir o que o outro expressa de si para o mundo e enxergar seus agenciamentos, para assim afetar e ser afetado, como afirma o filósofo Gilles Deleuze (2002).

Segundo Barreiro, Carvalho e Furlan (2018), o afeto de tristeza precisa ser legitimado e por conseguinte, trabalhado. Visto que o vínculo educador/a-estudante e escola-estudante se estabelece pelo encantamento dessas relações.

No âmbito da sensibilidade deixa-se de diferenciar mente e corpo e vê-se todo um indivíduo que se afeta com estímulos intelectuais e sensoriais, dados pelas relações. Um movimento regido pelo contato. Segundo Baker (1980 apud BARREIRO, CARVALHO, FURLAN, 20I8), entrar em contato consigo mesmo, significa ter total dimensão de seus sentimentos e como seu corpo reage a eles. Tratase de um fluxo intenso de energias que corre pelo corpo e os afetos são expressados pelos órgãos, visceralmente. Enquanto educadora ou educador, fazer desse contato o ponto de partida da relação com o/a estudante, significa abrir um campo de inúmeras possibilidades de serem quem quiserem ser, livres. É um espaço-tempo em potencial de troca de conhecimentos e autoconhecimento.

Contudo, ao tomarmos consciência da influência que temos na vida do outro como educador, o autocuidado se torna prioridade. Se escutar, se sentir, se acolher e cuidar-se. Isto não significa que precisamos estar sempre bem-dispostos às relações e só assim elas serão proveitosas. Pelo contrário, autoconhecer-se também é respeitar os próprios limites. Bem como para outra parte da relação, entender e acolher o momento do outro. Mesmo sendo uma das partes, uma criança.

A energia que circunda esta troca de afeto é absorvida naturalmente pelas crianças sem necessariamente precisar ser verbalizada. O fluxo de responsabilizar-se de si e consequentemente do outro, é cíclico, altruísta. Dispensa-se aqui, o lugar de adulto autoritário, como se por ter mais tempo de vida e/ou bagagem acadêmica detivesse um saber fundamental. $E$ sim, alguém inteiro e presente para os momentos de troca. Ser autoridade no sentido de dispor de capacidades de proteção, que transpasse segurança para a criança. Mas jamais cerceando o caminhar dela. 
$\mathrm{Na}$ educação infantil, bem mais que compartilhar conteúdos, é no cuidar desse corpo que expressa sentimentos, emoções, desejos e tudo, por meio de gestos faciais ou choros, que surgem as relações emocionais entre educador/a-estudante. Segundo Andrada, Dugnani, Petroni e Souza (2019), trabalhar e vivenciar a potência dos afetos no desenvolvimento, pode produzir amplitude de consciência de si, do outro e do campo.

Sobre estes estímulos sensoriais, tenho um momento de cuidado, que os abrange num só momento, o carinhoso "chameguinho". É quando aconchego a criança no colo, a deito, abraço e dou beijinhos no rosto e pescoço, ao mesmo tempo; repetidas vezes. $O$ ato de amor e carinho que sempre me dispus a fazer foi simbolizado com um nome e forma. Até que as próprias crianças começaram a pedir o "chameguinho", com falas do tipo: " - Anna, eu quero ficar de chameguinho com você hoje" me abraçando e dando beijinhos. Então fui atravessada pelo vínculo de afeto firmado naquele gesto. Onde as vezes consigo perceber carências emocionais, expressadas por pequenas falas e olhares; ou mesmo pequenas lesões não sentidas a priori pela criança. Um espaço-tempo de cuidado singelo e enriquecedor.

Nosso corpo nos conduz à muitos lugares, nos defende, é morada de tudo que sentimos. É na educação infantil que a principal referência da criança, a mãe, o pai ou quem a cuida diretamente, confia este papel a um desconhecido, à educadora ou educador. Bem como a um ambiente totalmente novo e envolto de estímulos diversos, além de muitas outras crianças, a escola. É em meio a isto, que o corpo geralmente se enrijece, se armando até que se crie confiança no outro. Com olhar sensível a todo esse processo, além do prazer inenarrável dessa troca genuína com as crianças, me dou conta do quão especial se tornou o "chameguinho". E, então percebi o movimento de afetar e ser afetada em minha prática.

Uma criança em sua vulnerabilidade dependente do adulto como apoio simbólico de suas emoções. E, é deste lugar, em estado de inteira disponibilidade, que nos permitimos ser afetados por esses estímulos e assim possamos apresentar a essa criança possibilidades de expressar o que deseja. A troca de afeto que acontece nessa relação promove um vínculo genuíno envolto de confiança e segurança, no outro.

Pautada num modelo de educação que não possui limites territoriais e relacionais, os indivíduos são constantemente estudantes e educadores. Pessoas que convivem e desenvolvem-se juntos, por seus encontros. Seres que se dispõem como fontes e canais de afetos. Reverberam potências individuais e conjuntas. Um fluxo de aprendizagem contínua sem um roteiro conteudista.

Portanto, o/a educador/a está para alguém que se dispõe a relacionar-se, com pretensão ou não de um ciclo de aprendizagem. Mas como uma ponte, no sentido de facilitar possibilidades para o desabrochar de potências, de um/a ou um grupo de estudantes. Com o desenvolvimento da 
verbalização, ser espectadora dos acontecimentos exatos, que se tornarão memória para aquele indivíduo em formação. Ser colo, abraço ou olhar, de afago, gerar afetividade.

Enquanto "professor/a" etimologicamente significa o/a que detém saber e o ministra a outrem. Logo, se institui uma relação de poder entre duas partes, onde uma se sobrepõe a outra por dispor de mais conhecimento. Na educação tradicional, esse lugar é enfatizado pela hierarquia proposta nas escolas, quando as regras são ditadas pelo corpo docente da instituição; ou quando as relações são verticalizadas, entre funcionários/as e estudantes.

Defende-se aqui uma educação com respeito aos afetos que nos atravessam, uma educação vivencial, relacional e por consequência horizontal. Portanto, nesta proposta se houver uma escola ou não, todes serão educadores ou educadoras. Independente de cargos ou diplomas, cada um em sua capacidade e área de saber. No entanto, entendendo que nossa vida é um compilado de relações, mesmo sem a intenção somos constantemente estudantes e educadores(as) desde que despertamos ou nos despertam interesse.

Segundo Deborah Sayão (2005), se o cuidar significa sair da inércia e atender uma demanda do outro, somente como uma atitude altruísta, pautando nossa vivência como dependente de relação com o outro, a mesma não deveria ser só aplicada na educação infantil.

\section{Considerações momentâneas}

Por muito tempo, os olhares para a primeira infância se sustentaram no fator de cuidado físico, ou acolhimento das demandas imediatas. Ainda assim, mesmo que de forma não perceptível até então, os afetos já atravessavam as relações entre as crianças pequenas. Bem como o caminhar natural de desenvolvimento intelectual e físico. E então, se institucionaliza o espaço restrito à educação, a escola. Um lugar para educar o corpo e a mente, de forma que o indivíduo consiga se inserir socialmente sem grandes obstáculos, tendo em vista seu eixo de normalidade.

No entanto, se entendermos a educação a partir das relações e com base nos inúmeros afetos que circulam esses encontros, emergimos aí uma nova forma de escolarização. Onde na verdade o título institucional não é necessário, já que os muros não existem mais. Uma educação livre, que ao contrário de cercear espaços pessoais e estruturais (espaços físicos), dê subsídio para a criação; acolha os afetos, mas não os limitando e sim potencializando. Uma forma de produzir educação entendendo indivíduos como um todo, independente de idade. Mesmo que haja escola, de qualquer que seja a faixa etária, que os diálogos afetivos abram campos criativos, inventivos.

Ao longo desse manuscrito, como uma artesania, como um fazer com a partir de processos do caminhar, histórias foram contadas dessa experimentação docente-discente, colocando a relação, 
o encontro e os afetos no centro do processo, não como algo que deve ser deslegitimado ou ignorado para que se possa prestar atenção nos conteúdos, nos livros ou nos métodos a priori adotados. A educação se faz no encontro. Aposta-se que os/as educadores/as possam transgredir o papel prédefinido pela educação tradicional, de professor e professora, podendo se oportunizar com os papéis que escolherem frente às relações que surgirem. Um espaço-tempo, onde as próprias possibilidades sejam a ponte relacional entre educador/estudante.

\section{Referências:}

ANDRADA, P. C. de; DUGNANI, L. A. C.; PETRONI, A. P.; SOUZA, V. L. T. de. Atuação de Psicólogas (os) na Escola: enfrentando desafios na proposição de práticas críticas. Psicologia: Ciência e Profissão, Brasília, v. 39, n. I, 2019.

LISBOA, F. de A.; CUNHA, T. C.; BICALHO, P. P. G. de. Para uma educação inventiva: a circulação de palavras e grupos de análise dos processos de escolha como afirmação de potência. REXE Revista de Estudios y Experiencias en Educación, v.2, p.I-16, 2018.

BAKER, E. F. Problemas de Contato. In: BAKER, E. F. O labirinto humano causas do bloqueio da energia sexual: Novas buscas em psicoterapia. 13 ed. São Paulo: Summus editorial, 1980.

BARREIRO, M. F.; CARVALHO, A. B.; FURLAN, M. R. A arte e o afeto na inclusão escolar: potência e o pensamento não representativo. Childhood \& Philosophy, Rio de Janeiro, v. 14, n. 30, p.5 I7$534,2018$.

BRASIL. Lei $\mathbf{n}^{\circ}$ 9.394, de 20 de dezembro de 1996. Estabelece as diretrizes e bases da educação nacional. Brasília, DF. 1996.

CARVALHO, M. P. de. Ensino, uma atividade relacional. Revista Brasileira de Educação, São Paulo, n. II, p. 17-32, 1999.

DAYRELL, J. A escola como espaço sociocultural. In: Dayrell, J. (Org.). Múltiplos olhares sobre educação e cultura. $2^{\mathrm{a}}$. reimpressão. Belo Horizonte: UFMG, 2003.

DELEUZE, G. Espinoza: filosofia prática. Tradução de Daniel Lins e Fabien Pascal Lins. São Paulo: Escuta, 2002.

FREIRE, P. Pedagogia do Oprimido. 42 ed. Rio de Janeiro: Paz e Terra, 2005.

FREIRE, P. Ensinar exige consciência do inacabado. In: Freire, Paulo. Pedagogia da autonomia: saberes necessários à prática educativa. 54 ed. Rio de Janeiro: Paz e Terra, 2016.

HOOKS, B. Ensinando a transgredir: a educação como prática de liberdade. $2^{\mathrm{a}}$ ed. São Paulo: Editora WMF Martins Fontes, 2017.

INKIRI, T. Educação Consciente - Escola Viva Inkiri. Maraú: Editorial Inkiri; Centro de Realização do Ser - Piracanga, 2014. 
LAZZAROTO, G.; CARVALHO, J. Afetar. In: FONSECA, T.; NASCIMENTO, M. L. do;

MARASCHIN, C. Pesquisar na diferença: um abecedário. Porto Alegre: Editora Sulina, 2012.

LOURAU, R. Análise Institucional e Práticas de Pesquisa. Rio de Janeiro: Ed.UERJ, 1993.

MATTOS, A. R.; PÉREZ, B. C.; ALMADA, C. V. R.; CASTRO, L. R. de. O cuidado na relação professor-aluno e sua potencialidade política. Estudo de Psicologia, Natal, v. I8, n. 2, p. 369-377, jun, 2013.

MOEHLECKE, V. Oficinar. In: FONSECA, T.; NASCIMENTO, M. L. do; MARASCHIN, C. Pesquisar na diferença: um abecedário. Porto Alegre: Editora Sulina, 2012.

MORAES, M. PesquisarCOM: política ontológica e deficiência visual. In: MORAES, M.; KASTRUP, V. Exercícios de ver e não ver: arte e pesquisa com pessoas com deficiência visual. Rio de Janeiro: Nau Editora, 2010.

PASSOS, E.; KASTRUP; V.; ESCÓSSIA, L. da. (Orgs.). Pistas do método da cartografia: Pesquisa-intervenção e produção de subjetividade. Porto Alegre: Sulina., 2015.

PIRACANGA (s/a). Escola Inkiri. Disponível em: https://piracanga.com/projetos/escola-inkiri/. Acesso em: 24 nov. 2019.

ROMANO, G. Imagens da juventude na era moderna. In: LEVI, G; SCHIMIDT, J. (Org.). História dos Jovens 2. São Paulo: Companhia das Letras, 1996.

SAGRADO, A.; PEREZ, R.; GUEDES, A. [diretores]. Quando sinto que já sei [filme]. Belo Horizonte: Despertar Filmes. 78min. Colorido, 2014.

SANTOS, D. C. C. dos. O cuidado no espaço escolar: ampliando as possibilidades de cuidar. Estudos e pesquisas em psicologia, Rio de Janeiro, v. I5, n. spe, p. I329-I344, dez, 2015.

SAYÃO, D. T. Relações de gênero e trabalho docente na educação infantil: um estudo de professores em creche. 2005. 274 fls. Tese (Doutorado). Universidade Federal de Santa Catarina. Florianópolis, 2005.

SAYÃO, D. T. Não basta ser mulher... não basta gostar de crianças... "Cuidado/educação" como princípio indissociável na Educação Infantil. Educação (UFSM), vol. 35, n. I, p. 69-84, Jan./Abr, 2010.

SOARES, L. Um convite para um começo de conversa sobre a graduação em Psicologia: pensando uma versão da Psicologia do Desenvolvimento pela TAR. Estudo e pesquisa em psicologia. Rio de Janeiro, v. I5, n 4, p. I303-1228, Dez, 2015.

THOMAZ, A. O vazio de todas as coisas! Piracaia: Amalaya, 2019.

TIMM, F.; PEREIRA, O. Teoria dos afetos de Espinosa: ruptura com as servidões em psicologia. In: LEMOS, F.; GALINDO, D.; BICALHO, P.; OLIVEIRA, F.; SANTOS, I.; SANTOS, A.; ELMENESCANY, E.; ALMEIDA, M. (Orgs.). Criações transversais com Gilles Deleuze: artes, saberes e política. Curitiba: Editora CRV, 2016. 
TRINDADE, A. L.; BRANDÃO, A. P. (Orgs.). A Cor da cultura - Modos de brincar: caderno de atividades, saberes e fazeres. Rio de Janeiro: Fundação Robero Marinho, 2010.

TRINDADE, A. L. da. Olhando o com coração e sentindo com o corpo inteiro no cotidiano escolar. In: TRINDADE, A. L. da; SANTOS, R. dos. (Orgs.) Multiculturalismo: mil e uma faces da Escola. Rio de Janeiro: DP\&A, 160p, 1999.

TRINDADE, A. L. A Cor da cultura - Saberes e fazeres, v. I: modos de ver. Rio de Janeiro: Fundação Roberto Marinho, 2006.

Recebido em: 07 de dezembro de 2020.

Versão corrigida recebida em: 02 de julho de 202I.

Aceito em: 29 de outubro de 2021 .

Publicado online em: II de fevereiro de 2022. 